\title{
Valve replacement surgery for older individuals with preoperative atrial fibrillation: The effect of prosthetic valve choice and surgical ablation
}

\author{
Ho Jin Kim, MD, Joon Bum Kim, MD, PhD, Sung-Ho Jung, MD, Suk Jung Choo, MD, PhD, \\ Cheol Hyun Chung, MD, PhD, and Jae Won Lee, MD, PhD
}

Objective: Prosthetic valve type selection combined with surgical ablation during left-sided heart valve replacement in older individuals with atrial fibrillation remains controversial.

\begin{abstract}
Methods: A total of 573 patients aged 60 years or older (median, 65; range, 60-84) who underwent left-sided valve replacement surgery in the presence of atrial fibrillation from 1990 to 2010 were evaluated for all-cause mortality during a median follow-up period of 58.0 months (interquartile range, 33.1-84.1).
\end{abstract}

\begin{abstract}
Results: Mechanical and bioprosthetic valves were implanted in $356(62.1 \%)$ and $217(37.9 \%)$ patients, respectively, and 203 patients $(35.4 \%$ ) underwent surgical ablation concomitantly. During the follow-up period, 166 patients died. The 5- and 10- year survival rate was $76.3 \% \pm 2.1 \%$ and $58.4 \% \pm 3.2 \%$, respectively. On Cox regression analysis, age $(P<.001)$, diabetes $(P=.014)$, left ventricular ejection fraction $(P=.010)$, left atrial size $(P=.038)$, the requirement for coronary bypass $(P=.015)$, and cardiopulmonary bypass time $(P<.001)$ emerged as significant and independent predictors of death. In addition, surgical ablation was protective against all-cause mortality (hazard ratio, $0.63 ; P=.033$ ). The improved survival observed with surgical ablation was verified by propensity score adjustment models (hazard ratio, $0.64 ; 95 \%$ confidence interval, $0.30-0.99 ; P=.046)$. The choice of prosthetic type, however, affected neither survival $(P=.79)$ nor event-free survival $(P=.48)$.
\end{abstract}

Conclusions: Long-term survival after valve replacement in older individuals with atrial fibrillation was affected by several preoperative characteristics and the performance of surgical ablation but not by the choice of prosthesis. These findings suggest that surgical atrial fibrillation ablation should always be considered for these patients, regardless of the prosthesis type used. (J Thorac Cardiovasc Surg 2014;147:1907-17)

Valve replacement surgery remains a standard therapy for symptomatic patients with severe heart valve disease, whose dysfunctional valves are not amendable to repair. When performing valve replacement surgery, the choice of prosthetic valve type depends mostly on patient-related factors, among which age has been regarded as the key determining factor. ${ }^{1-3}$ Current guidelines suggest that bioprosthetic implantation is a reasonable option for older individuals because of the lower rates of anticoagulationrelated bleeding, despite comparable rates of valve failure. ${ }^{2,3}$

However, this age-guided recommendation might not be applicable to patients at significant risk of

\footnotetext{
From the Department of Thoracic and Cardiovascular Surgery, Asan Medical Center, University of Ulsan College of Medicine, Seoul, Republic of Korea.

Disclosures: Authors have nothing to disclose with regard to commercial support.

Received for publication April 25, 2013; revisions received June 20, 2013; accepted for publication July 3, 2013; available ahead of print Aug 30, 2013.

Address for reprints: Jae Won Lee, MD, PhD, Department of Thoracic and Cardiovascular Surgery, Asan Medical Center, University of Ulsan College of Medicine, 88, Olympic-Ro 43-Gil, Songpa-Gu, Seoul 138-736, Republic of Korea (E-mail: jwlee@amc.seoul.kr).

$0022-5223 / \$ 36.00$

Copyright (C) 2014 by The American Association for Thoracic Surgery

http://dx.doi.org/10.1016/j.jtcvs.2013.07.019
}

thromboembolism, such as those with atrial fibrillation (AF). AF is the most common arrhythmia in patients undergoing valve replacement surgery, and its prevalence is reported to be as high as $30 \%$ to $50 \%{ }^{4} \mathrm{AF}$ is regarded as a marker of prolonged and advanced valve dysfunction and has been reported to be associated with poor clinical outcomes after heart valve surgery. ${ }^{5}$ Surgical ablation has been recognized as an effective method of restoring normal sinus rhythm from AF and, consequently, has gained popularity as a concomitant procedure during heart valve surgery. ${ }^{5,6}$

Despite the progress in AF ablation surgery, the high rate of $\mathrm{AF}$ recurrence in older individuals ${ }^{6,7}$ and concerns about the increased surgical risks due to procedural complexity ${ }^{8}$ have hindered the routine combination of surgical ablation in older individuals undergoing valve replacement surgery. Furthermore, combining surgical ablation and valve replacement surgery in patients with AF complicates the choice of prosthetic valve type (mechanical vs bioprosthetic valve) that will be implanted.

Thus, evaluation of the clinical outcomes in older patients with AF undergoing valve replacement surgery according to the choice of prosthetic valve type and the performance of surgical ablation is important. In the review 


$$
\begin{aligned}
& \text { Abbreviations and Acronyms } \\
& \begin{aligned}
\mathrm{AF} & =\text { atrial fibrillation } \\
\mathrm{CABG} & =\text { coronary artery bypass grafting } \\
\mathrm{HR} & =\text { hazard ratio } \\
\mathrm{INR} & =\text { international normalized ratio } \\
\mathrm{LV} & =\text { left ventricular }
\end{aligned}
\end{aligned}
$$

of previously published data, however, few studies were found that had evaluated the clinical effect of these procedural factors on the clinical outcomes in reasonably sized cohorts. We, therefore, sought to evaluate the long-term clinical outcomes of valve replacement surgery, taking into account the type of prosthetic valve implanted and the performance of concomitant surgical ablation, in a reasonably sized cohort of older patients with AF.

\section{METHODS \\ Study Population}

From January 1990 to December 2010, 1627 patients, aged 60 years or older, had undergone left-sided valve replacement surgery at the Asan Medical Center (Seoul, South Korea). These patients were prospectively registered in the database at our institution. The database includes the baseline patient characteristics, results of cardiac evaluations, and detailed information about surgery. Of the 1627 patients, 615 were identified as having preoperative AF. To form a homogeneous study population, those who had undergone concomitant right-sided valve replacement, aortic root replacement, or correction of complex congenital heart disease were excluded. Finally, 573 patients, aged 60 years or older (median, 65; range, 60-84), who had undergone left-sided valve replacement with either a mechanical or bioprosthetic valve were enrolled in the present study.

The institutional ethics committee and review board at the Asan Medical Center approved the present study (no. S2012-1476-0001). The requirement for informed patient consent was waived owing to the retrospective nature of the study.

\section{Prosthesis Choice and Surgical Procedures}

The attending surgeons explained the pros and cons of combining surgical ablation with valve replacement, and the types of prosthetic valves available (mechanical vs bioprosthetic). Decisions on the optimal approach were made after thorough discussions, with patient input heavily reflected. The surgical AF ablation procedures were performed using cryoablation $(\mathrm{n}=165,81.3 \%)$ or microwave $(\mathrm{n}=36,17.7 \%)$, or both sources of ablation $(\mathrm{n}=2,1.0 \%)$. The lesion sets for the procedure have been previously described. ${ }^{9}$ Of the present study cohort, $87(42.9 \%)$ received left atrium ablation, and $116(57.1 \%)$ received biatrial ablation. During mitral valve replacement, the surgeons attempted to retain as much subvalvular apparatus as possible using chordal-sparing methods.

\section{Postoperative Management}

Postoperatively, all patients who underwent mechanical valve replacement were anticoagulated with warfarin, with a target international normalized ratio (INR) of 2.0 to 3.0. For the patients who underwent bioprosthetic valve replacement, anticoagulation with warfarin was routinely maintained for 3 to 6 months, with a target INR of 1.5 to 2.5 . Subsequent maintenance of anticoagulation therapy was determined according to the individual risk factors for thromboembolism. Postoperative AF or the absence of effective atrial contraction resulted in
TABLE 1. Baseline characteristics stratified by surgical ablation

\begin{tabular}{lccr}
\hline \multicolumn{1}{c}{ Characteristic } & $\begin{array}{c}\text { Ablation } \\
\text { group }\end{array}$ & $\begin{array}{c}\text { Control } \\
\text { group }\end{array}$ & $\begin{array}{c}\boldsymbol{P} \\
\text { value }\end{array}$ \\
\hline Patients (n) & 203 & 370 & \\
Age (y) & $66.3 \pm 4.8$ & $66.6 \pm 5.4$ & .485 \\
Male gender (\%) & $61(30.0)$ & $168(45.4)$ & $<.001$ \\
NYHA functional class & & & \\
I & $40(19.7)$ & $46(12.4)$ & \\
II & $79(38.9)$ & $134(36.2)$ & \\
III & $77(37.9)$ & $156(42.2)$ & \\
IV & $7(3.4)$ & $34(9.2)$ & \\
Diabetes mellitus & $36(17.7)$ & $47(12.7)$ & .108 \\
Hypertension & $56(27.6)$ & $87(23.5)$ & .313 \\
History of CVA/TIA & $37(18.2)$ & $57(15.4)$ & .410 \\
Previous cardiac surgery & $10(4.9)$ & $37(10.0)$ & .038 \\
Estimated GFR & $70.5 \pm 18.2$ & $67.3 \pm 21.7$ & .078 \\
CHADS score & & & \\
0 & $87(42.9)$ & $161(43.5)$ & \\
1 & $56(27.6)$ & $99(26.8)$ & \\
2 & $32(15.8)$ & $67(18.1)$ & \\
3 & $18(8.9)$ & $32(8.6)$ & \\
4 & $8(3.9)$ & $10(2.7)$ & \\
5 & $2(1.0)$ & $1(0.3)$ & \\
Echocardiographic data & & & \\
LV ejection fraction $(\%)$ & $53.9 \pm 8.9$ & $53.5 \pm 11.2$ & .616 \\
LV end-systolic dimension $(\mathrm{mm})$ & $35.9 \pm 8.1$ & $38.0 \pm 9.4$ & .007 \\
LV end-diastolic dimension $(\mathrm{mm})$ & $52.8 \pm 8.6$ & $55.1 \pm 10.0$ & .003 \\
Left atrial diameter (mm) & $58.3 \pm 9.8$ & $59.2 \pm 12.2$ & .364 \\
RV-RA pressure gradient (mm Hg) & $37.7 \pm 12.8$ & $40.0 \pm 16.6$ & .074 \\
Ticuspid & & &
\end{tabular}

Tricuspid regurgitation grade

$\begin{array}{rrr}0 & 11(5.4) & 39(10.5) \\ 1 & 46(22.7) & 114(30.8) \\ 2 & 48(23.6) & 79(21.4) \\ 3 & 54(26.6) & 61(16.5) \\ 4 & 44(21.7) & 77(20.8)\end{array}$

Operation type

AV replacement $\quad 43(21.2) \quad 101(27.3)$

MV replacement $\quad 126(62.1) \quad 210(56.8)$

$\mathrm{AV}$ and MV replacement $\quad 34(16.7) \quad 59(15.9)$

$\begin{array}{llll}\text { Concomitant tricuspid repair } & 119(58.6) & 139(37.6) & <.001\end{array}$

Other concomitant surgery

CABG

Aorta replacement

$22(10.8) \quad 43(11.6) \quad .777$

$3(1.5) \quad 11(3.0) \quad .268$

$\begin{array}{lllll}\text { Aortic crossclamp time (min) } & 109.9 \pm 36.3 & 84.7 \pm 42.6 & <.001\end{array}$

$\begin{array}{lllll}\text { Cardiopulmonary bypass time }(\mathrm{min}) & 201.1 \pm 53.9 & 140.7 \pm 77.2 & .035\end{array}$

\begin{tabular}{llll} 
Logistic EuroSCORE II (\%) & $3.24 \pm 2.84$ & $4.22 \pm 4.83 \quad .003$ \\
\hline D
\end{tabular}

Data presented as mean \pm standard deviation or $\mathrm{n}(\%)$. NYHA, New York Heart Association; CVA, cerebrovascular accident; TIA, transient ischemic attack; $G F R$, glomerular filtration rate; $L V$, left ventricular; $R V$, right ventricular; $R A$, right atrial; $A V$, aortic valve; $M V$, mitral valve; $C A B G$, coronary artery bypass grafting; $\mathrm{CHADS}_{2}$, Congestive heart failure, Hypertension, Age $>75$ years, and Diabetes mellitus.

prolonged anticoagulation therapy until both sinus rhythm and atrial contractility had been restored. Patients with inadequate INR values were followed up on a weekly basis until the target INR values were achieved, after which, the warfarin doses were adjusted on an outpatient basis every 3 months.

Patients who underwent surgical ablation were treated with a "rhythm control strategy," which involved class I or III antiarrhythmic 
TABLE 2. Baseline characteristics stratified by prosthetic valve type

\begin{tabular}{|c|c|c|c|}
\hline Characteristic & Mechanical & Bioprosthesis & $\begin{array}{c}P \\
\text { value }\end{array}$ \\
\hline Patients (n) & 356 & 217 & \\
\hline Age (y) & $64.3 \pm 3.9$ & $70.1 \pm 5.2$ & $<.001$ \\
\hline Male gender & $139(39.0)$ & $90(41.5)$ & .565 \\
\hline \multicolumn{4}{|l|}{ NYHA functional class } \\
\hline I & $62(17.4)$ & $24(11.1)$ & \\
\hline II & $139(39.0)$ & $74(34.1)$ & \\
\hline III & $131(36.8)$ & $102(47.0)$ & \\
\hline IV & $24(6.7)$ & $17(7.8)$ & \\
\hline Diabetes mellitus & $48(13.5)$ & $35(16.1)$ & .394 \\
\hline Hypertension & $91(25.6)$ & $52(24.0)$ & .692 \\
\hline History of CVA/TIA & $57(16.0)$ & $37(17.1)$ & .816 \\
\hline Previous cardiac surgery & $27(7.6)$ & $20(9.2)$ & .531 \\
\hline Estimated GFR & $70.0 \pm 19.6$ & $65.9 \pm 22.0$ & .021 \\
\hline \multicolumn{4}{|l|}{$\mathrm{CHADS}_{2}$ score } \\
\hline 0 & $171(48.0)$ & $77(35.5)$ & \\
\hline 1 & $92(25.8)$ & $63(29.0)$ & \\
\hline 2 & $49(13.8)$ & $50(23.0)$ & \\
\hline 3 & $31(8.7)$ & $19(8.8)$ & \\
\hline 4 & $10(2.8)$ & $8(3.7)$ & \\
\hline 5 & $3(0.8)$ & $0(0)$ & \\
\hline \multicolumn{4}{|l|}{ Echocardiographic data } \\
\hline LV ejection fraction $(\%)$ & $54.3 \pm 9.4$ & $52.6 \pm 11.6$ & .063 \\
\hline LV end-systolic dimension (mm) & $36.8 \pm 8.2$ & $38.0 \pm 9.8$ & .104 \\
\hline LV end-diastolic dimension (mm) & $53.6 \pm 9.1$ & $55.5 \pm 10.1$ & .021 \\
\hline Left atrial diameter $(\mathrm{mm})$ & $59.3 \pm 11.1$ & $58.1 \pm 11.5$ & .227 \\
\hline $\mathrm{RV}$-RA pressure gradient $(\mathrm{mm} \mathrm{Hg})$ & $38.8 \pm 14.0$ & $39.1 \pm 15.6$ & .841 \\
\hline \multicolumn{4}{|l|}{ Tricuspid regurgitation grade } \\
\hline 0 & $29(8.1)$ & $21(9.7)$ & \\
\hline 1 & $102(28.7)$ & $58(26.7)$ & \\
\hline 2 & 77 (21.6) & $50(23.0)$ & \\
\hline 3 & $72(20.2)$ & $43(19.8)$ & \\
\hline 4 & $76(21.3)$ & $45(20.7)$ & \\
\hline \multicolumn{4}{|l|}{ Operation type } \\
\hline AV replacement & $67(18.8)$ & $77(35.5)$ & \\
\hline MV replacement & $221(62.1)$ & $115(53.0)$ & \\
\hline $\mathrm{AV}$ and $\mathrm{MV}$ replacement & $68(19.1)$ & $25(11.5)$ & \\
\hline Concomitant tricuspid repair & $167(46.9)$ & $91(41.9)$ & .261 \\
\hline \multicolumn{4}{|l|}{ Other concomitant surgery } \\
\hline CABG & $21(5.9)$ & $44(20.3)$ & $<.001$ \\
\hline Aorta replacement & $6(1.7)$ & $8(3.7)$ & .165 \\
\hline Aortic crossclamp time (min) & $90.8 \pm 41.0$ & $98.5 \pm 43.8$ & .036 \\
\hline Cardiopulmonary bypass time (min) & $168.6 \pm 41.3$ & $151.6 \pm 64.8$ & .55 \\
\hline Logistic EuroSCORE II (\%) & $3.03 \pm 2.69$ & $5.25 \pm 5.76$ & $<.001$ \\
\hline
\end{tabular}

Data presented as mean \pm standard deviation or $\mathrm{n}(\%)$. NYHA, New York Heart Association; CVA, cerebrovascular accident; TIA, transient ischemic attack; $G F R$, glomerular filtration rate; $L V$, left ventricular; $R V$, right ventricular; $R A$, right atrial; $A V$, aortic valve; $M V$, mitral valve; $C A B G$, coronary artery bypass grafting; $C H A D S_{2}$, Congestive heart failure, Hypertension, Age $>75$ years, and Diabetes mellitus.

medication, when atrial arrhythmias were detected postoperatively. Among the study cohort who received surgical ablation $(\mathrm{n}=203)$, 66 patients $(32.5 \%)$ were discharged with class I or III medications. Those medications were discontinued on an outpatient basis once the restoration of normal sinus rhythm had been confirmed. The patients who failed to achieve "AF-free" status after treatment with these drugs were switched to a "rate control strategy," which involved
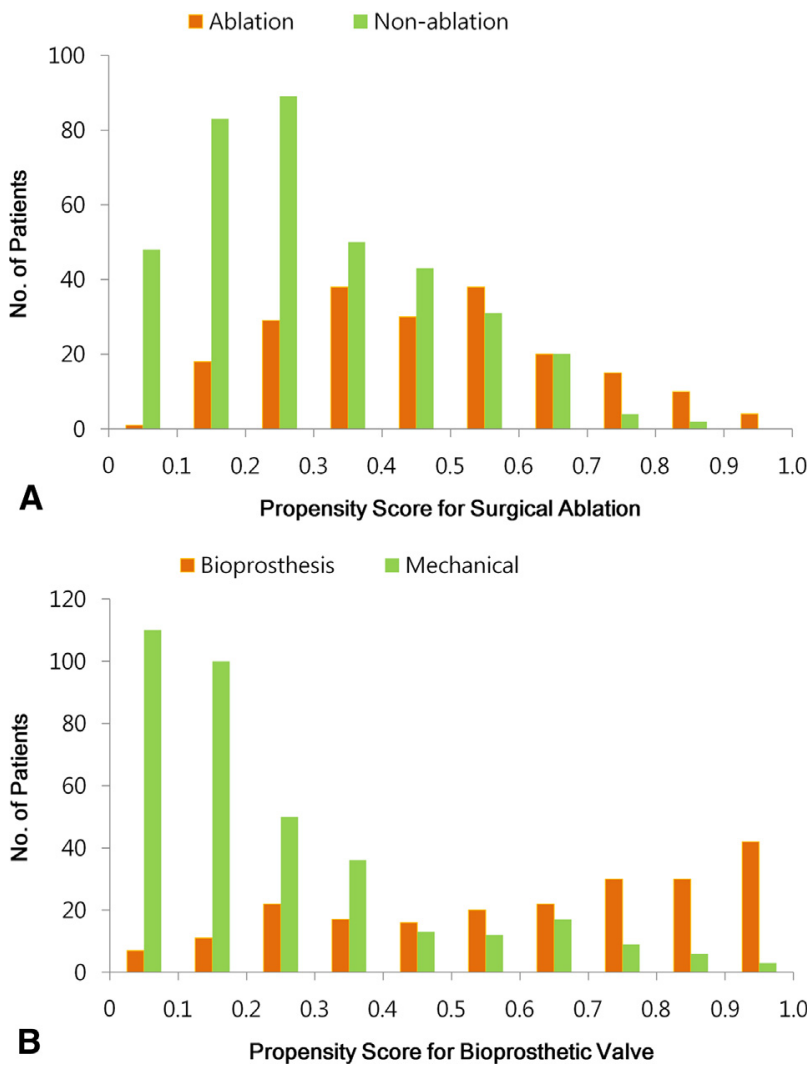

FIGURE 1. Propensity scores for A, surgical ablation and B, bioprosthetic valve. Each model had a $\mathrm{C}$ statistic of 0.72 and a Hosmer-Lemeshow goodness-of-fit $P=.77$ (A) and a $\mathrm{C}$ statistics of 0.43 and a Hosmer-Lemeshow goodness-of-fit $P=.84$ (B), indicating that both models were adequately calibrated, with strong discrimination.

digitalis, $\beta$-blockers, or calcium channel blockers to control the ventricular rate. The patients who did not undergo surgical ablation were treated with a rate control strategy.

\section{Definitions and Clinical Follow-up}

The primary outcome of interest was all-cause mortality, rather than cardiac death, because the former is the most robust and unbiased index with no adjudication requirement. ${ }^{10}$ Other outcomes of interest included the composite of valve-related complications. Valve-related morbidities were recorded according to the guidelines for reporting mortality and morbidity after cardiac valve interventions, including valve thrombosis, embolism, bleeding, operated valve endocarditis, and reoperation. ${ }^{11}$

Clinical follow-up information was taken every 3 to 6 months on an outpatient basis or by telephone and continued until the end of May 2012. The completeness of the data, including mortality, vital status, and date and cause of death, was validated by the Korean National Registry of Vital Statistics.

\section{Statistical Analysis}

Categorical variables are presented as frequencies and percentages, and continuous variables are presented as the mean \pm standard deviation. Differences in the baseline characteristics between the patient groups according to the different surgical strategies ("mechanical vs bioprosthetic valve" and "ablation vs nonablation") were compared using Student's $t$ test for continuous variables and the chi-square test or Fisher's exact test for categorical variables. 
TABLE 3. Clinical outcomes

\begin{tabular}{|c|c|c|c|c|c|c|}
\hline \multirow[b]{2}{*}{ Outcome } & \multicolumn{3}{|c|}{ Surgical ablation } & \multicolumn{3}{|c|}{ Prosthetic valve type } \\
\hline & $\begin{array}{c}\text { Ablation group } \\
(\mathbf{n}=\mathbf{2 0 3})\end{array}$ & $\begin{array}{c}\text { Control group } \\
(\mathbf{n}=\mathbf{3 7 0})\end{array}$ & $P$ value & $\begin{array}{c}\text { Mechanical } \\
(\mathbf{n}=\mathbf{3 5 6})\end{array}$ & $\begin{array}{c}\text { Bioprosthesis } \\
(\mathbf{n}=\mathbf{2 1 7})\end{array}$ & $P$ value \\
\hline All-cause mortality & $30(14.8)$ & $136(36.8)$ & $<.001$ & $82(23.0)$ & $84(38.7)$ & $<.001$ \\
\hline Cardiovascular death & $28(13.8)$ & 117 (31.6) & $<.001$ & $70(19.6)$ & $77(34.6)$ & $<.001$ \\
\hline Bleeding & $6(3.0)$ & $5(1.4)$ & & $4(1.1)$ & $7(3.2)$ & \\
\hline Thromboembolic & $0(0.0)$ & $6(1.6)$ & & $4(1.1)$ & $2(1.0)$ & \\
\hline Arrhythmia & $1(0.5)$ & $5(1.4)$ & & $2(0.6)$ & $4(1.8)$ & \\
\hline Heart failure & $2(1.0)$ & $6(1.6)$ & & $5(1.4)$ & $3(1.4)$ & \\
\hline Sudden death & $1(0.5)$ & $4(1.1)$ & & $4(1.1)$ & $1(0.5)$ & \\
\hline Unexplained & $18(8.8)$ & $91(24.5)$ & & $47(13.2)$ & $56(25.7)$ & \\
\hline Noncardiovascular death & $2(1.0)$ & $19(5.2)$ & .011 & $12(3.4)$ & $9(4.1)$ & .75 \\
\hline Respiratory disease & $0(0.0)$ & $9(2.4)$ & & $5(1.4)$ & $4(1.7)$ & \\
\hline Sepsis & $1(0.5)$ & $5(1.4)$ & & $3(0.9)$ & $3(1.4)$ & \\
\hline Cancer & $1(0.5)$ & $4(1.1)$ & & $4(1.1)$ & $1(0.5)$ & \\
\hline Miscellaneous & $0(0.0)$ & $1(0.3)$ & & $0(0.0)$ & $1(0.5)$ & \\
\hline \multicolumn{7}{|l|}{ Valve-related complications } \\
\hline Thromboembolic event & $4(2.0)$ & $14(3.8)$ & .23 & $13(3.7)$ & $5(2.3)$ & .37 \\
\hline Anticoagulation-related hemorrhage & $32(15.8)$ & $56(15.1)$ & .84 & $64(18.0)$ & $24(11.1)$ & .026 \\
\hline Prosthetic valve endocarditis & $4(2.0)$ & $9(2.4)$ & .72 & $7(2.0)$ & $6(2.8)$ & .53 \\
\hline Valve reoperation & $3(1.5)$ & $14(3.8)$ & .12 & $11(3.1)$ & $6(2.8)$ & .82 \\
\hline
\end{tabular}

Data presented as mean \pm standard deviation or $n(\%)$.

Kaplan-Meier curves were used to delineate survival and event-free survival, and log-rank tests were used to compare the between-group differences in survival rates. For the multivariate analyses, the Cox proportional hazards models were used to determine the risk factors for all-cause mortality and adverse events. The preoperative baseline variables, surgical factors, prosthetic valve types, and the performance of surgical ablation were evaluated in the models, and those with $P \leq 20$ on univariate analysis were candidates for the multivariate Cox models. Multivariate analyses involved a backward elimination technique, and only variables with $P<.10$ were used in the final model. The final models were validated in 1000 bootstrap samples. For additional verification of the results of the Cox regression analysis to compare "mechanical versus bioprosthetic valves" and "ablation versus nonablation," propensity score analyses were performed. ${ }^{12}$ The propensity scores were estimated without regard to the outcome variables by multiple logistic regression analysis. Two propensity score models were developed that included all the variables listed in Tables 1 and 2 (Figure 1). The propensity scores were incorporated into the Cox regression model as covariates to calculate the propensity-adjusted hazard ratio (HR).

All reported $P$ values were 2 -sided, and $P<.05$ was considered statistically significant. SPSS software, version 19 (IBM, Armonk, NY) was used for the statistical analysis.

TABLE 4. Rhythm outcomes of ablation group at last follow-up visit

\begin{tabular}{lcc}
\hline \multicolumn{1}{c}{ Outcomes } & Biatrial ablation & Left-sided ablation \\
\hline Patients (n) & 116 & 87 \\
Rhythm & & \\
$\quad$ Sinus rhythm & $81(69.8)$ & $61(70.1)$ \\
$\quad$ With antiarrhythmic drugs & $3(2.6)$ & $4(4.6)$ \\
Junctional rhythm & $4(3.4)$ & $2(2.3)$ \\
$\quad$ With antiarrhythmic drugs & $1(0.9)$ & $0(0.0)$ \\
PPM & $12(10.3)$ & $2(2.3)$ \\
Atrial fibrillation & $19(16.4)$ & $22(25.3)$ \\
\hline
\end{tabular}

Data presented as n (\%). PPM, Permanent pacemaker.

\section{RESULTS}

\section{Baseline Characteristics}

Surgical ablation was performed in 203 patients (35.4\%), and mechanical valves were implanted in 356 patients $(62.1 \%)$. The valve replacement positions were as follows: aortic valve in 144 patients $(25.1 \%)$, mitral valve in 336 patients $(58.6 \%)$, and double valves in 93 patients $(16.2 \%)$. Concomitant tricuspid valve repair and coronary artery bypass grafting (CABG) were performed in $258(45.0 \%)$ and $65(11.3 \%)$ patients, respectively. Of the 258 patients who underwent tricuspid valve repair, $119(46.1 \%)$ also underwent surgical ablation: left sided in 39 and biatrial in 80 . The baseline patient characteristics according to the performance of surgical ablation and the choice of prosthetic valve type are summarized in Tables 1 and 2, respectively.

Patients who underwent concomitant surgical ablation were biased toward female gender, larger systolic and diastolic left ventricular (LV) dimensions, a lower history of previous cardiac surgery, and a greater likelihood to undergo concomitant tricuspid repair compared with those who did not undergo surgical ablation. The estimated surgical mortality risk validated using EuroSCORE II was significantly greater in patients who did not undergo surgical ablation (Table 1).

The patients who underwent bioprosthetic valve replacement were older and were more likely to undergo concomitant CABG than those with mechanical valve replacement. The EuroSCORE II score was significantly greater in patients with bioprosthetic valve replacement (Table 2). 

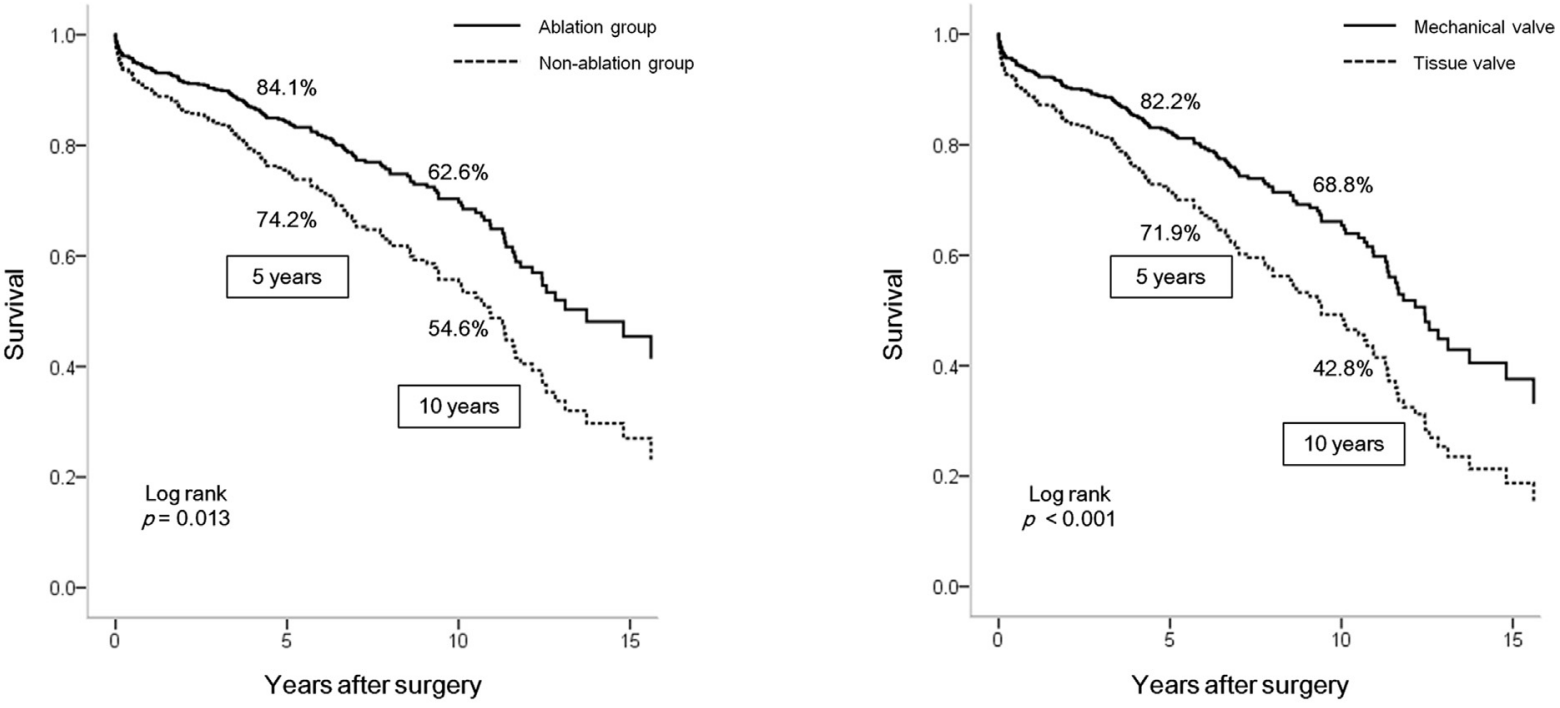

$\begin{array}{rcccc}\text { N. at risk } & & & & \\ \text { Ablation } & 203 & 61 & 10 & 0 \\ \text { A Control } & 370 & 176 & 62 & 8\end{array}$
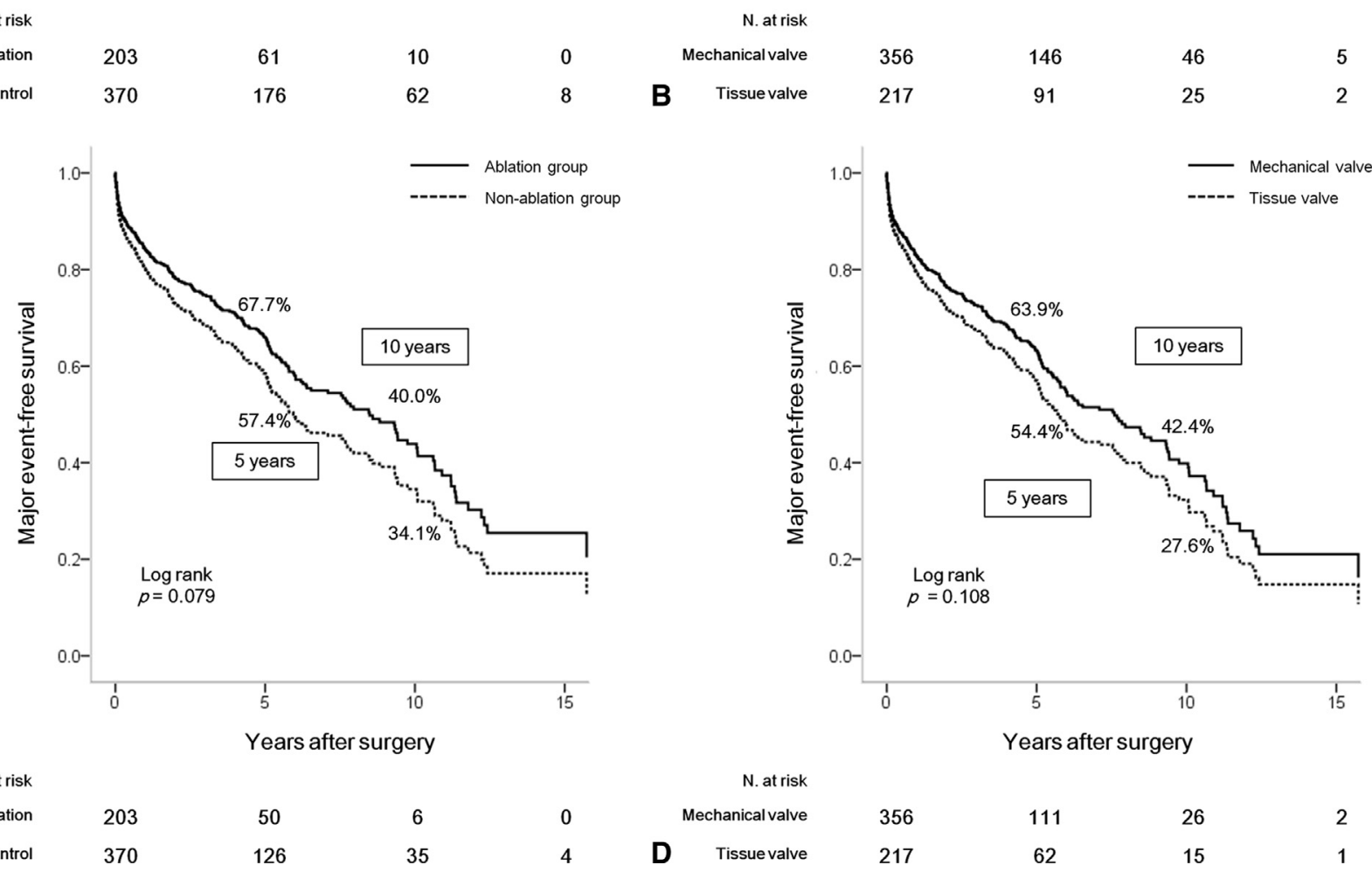

FIGURE 2. Unadjusted Kaplan-Meier curves for all-cause mortality according to the A, performance of surgical ablation, B, valve type, C, event-free survival according to the performance of surgical ablation, and D, event-free survival stratified by valve type. Major adverse valve-related events included thromboembolic events, bleeding, operated valve endocarditis, and reoperation.

The aortic crossclamping and cardiopulmonary bypass times were significantly longer in patients who underwent surgical ablation than those who did not (Table 1).

\section{Unadjusted Clinical Outcomes and Predictors of Mortality}

Early mortality occurred in 23 patients $(4.0 \%)$ and was not significantly affected by the use of surgical ablation (ablation vs nonablation, $3.9 \%$ vs $4.1 \% ; P>.99$ ) or the choice of prosthetic type (mechanical vs bioprosthetic valve, $3.1 \%$ vs $5.5 \%, P=.19$ ). During a median follow-up of 58.0 months (interquartile range, 33.1 to 84.1), 166 patients (29.0\%) died and 136 patients $(23.7 \%)$ experienced valve-related complications. The details of the adverse clinical outcomes according to the performance of surgical ablation and the choice of prosthetic valve type are listed in Table 3. A difference in mortality was found according to the performance of 
TABLE 5. Multivariate risk factor analysis for all-cause mortality (Cox regression)

\begin{tabular}{|c|c|c|c|c|}
\hline \multirow[b]{2}{*}{ Variable } & \multirow{2}{*}{$\frac{\text { Univariate }}{P \text { value }}$} & \multicolumn{3}{|c|}{ Multivariate analysis } \\
\hline & & HR & $95 \% \mathrm{CI}$ & $P$ value \\
\hline Age & $<.001$ & 1.077 & $1.046-1.110$ & $<.001$ \\
\hline Gender & .009 & & & \\
\hline Diabetes mellitus & .004 & 1.650 & $1.105-2.464$ & .014 \\
\hline Coronary artery disease & $<.001$ & 1.618 & $1.097-2.387$ & .015 \\
\hline Estimated GFR & .002 & 0.992 & $0.984-1.000$ & .052 \\
\hline \multicolumn{5}{|l|}{ Echocardiographic data } \\
\hline LV ejection fraction & .017 & 0.982 & $0.968-0.996$ & .010 \\
\hline LV end-systolic dimension & .004 & & & \\
\hline LV end-diastolic dimension & .007 & & & \\
\hline Left atrial diameter & .046 & 1.014 & $1.001-1.028$ & .038 \\
\hline RV-RA pressure gradient & .002 & 1.001 & $1.001-1.001$ & .060 \\
\hline \multicolumn{5}{|l|}{ Other concomitant surgery } \\
\hline CABG & $<.001$ & & & \\
\hline Aorta replacement & .009 & & & \\
\hline Aortic crossclamp time & .14 & & & \\
\hline Cardiopulmonary bypass time & $<.001$ & 1.001 & $1.001-1.001$ & $<.001$ \\
\hline Valve type & .001 & & & \\
\hline Surgical ablation & .014 & 0.634 & $0.417-0.964$ & .033 \\
\hline
\end{tabular}

Only variables with $P<.20$ on univariate Cox proportional hazards regression analysis were retained. $H R$, Hazard ratio; $C I$, confidence interval; $G F R$, glomerular filtration rate; $L V$, left ventricular; $R V$, right ventricular; $R A$, right atrial; $C A B G$, coronary artery bypass grafting.

surgical ablation (ablation vs nonablation, $14.8 \%$ vs $36.8 \% ; P<.001)$. In the surgical ablation group, no significant differences were found in overall survival (log-rank test, $P=.44$ ), event-free survival (log-rank test, $P=.20$ ), and freedom from cardiac death (log-rank test, $P=.30$ ) between the left-sided and biatrial groups. The rhythm outcome at the last follow-up according to the AF ablation lesion sets are listed in Table 4.

Figure 2 depicts the unadjusted Kaplan-Meier curves for all-cause mortality and major event-free survival according to the performance of surgical ablation and the choice of prosthetic valve type. The 5- and 10-year survival rates were $84.1 \%$ and $62.6 \%$ in the ablation group, $74.2 \%$ and $54.6 \%$ in the nonablation group $(P=.013$, Figure $2, A)$, $82.2 \%$ and $68.8 \%$ in the mechanical valve group, and $71.9 \%$ and $42.8 \%$ in the bioprosthetic valve group $(P<.001 ;$ Figure $2, B)$, respectively. The event-free survival tended to be superior for patients who underwent surgical ablation than for those who did not $(P=.079$; Figure 2, $C)$, and no significant difference was observed when stratified by the choice of prosthetic valve type $(P=.108$; Figure 2, D).

On multivariate Cox regression analysis, several significant and independent risk factors for all-cause mortality emerged, including older age, diabetes mellitus, requirement for concomitant $\mathrm{CABG}$, low $\mathrm{LV}$ ejection fraction, large left atrial diameter, long cardiopulmonary bypass time, and the absence of surgical ablation. The statistical significance of a low estimated glomerular filtration rate and pulmonary hypertension was marginal $(P=.05-.10$; Table 5$)$. The prosthetic valve type, however, did not emerge as a significant factor affecting mortality (it was eliminated at the second stage of stepwise Cox regression analysis).

\section{Adjusted Clinical Outcomes: Influence of Surgical Ablation and Prosthetic Valve Type}

The propensity score adjustment models revealed that surgical ablation was associated with a superior survival rate (HR, 0.64; 95\% confidence interval, 0.42-0.99; $P=.046$; Figure $3, A)$. In contrast, the prosthetic valve type did not significantly affect survival after propensity score adjustments (HR, 1.05; 95\% confidence interval, $0.72-1.54, P=.792$; Figure $3, B$ ). Similarly, surgical ablation tended to decrease the overall adverse clinical outcomes (Figure 3,C), but the prosthetic valve type did not significantly influence event-free survival (Figure 3,D).

For additional verification, Figure 4 shows the survival curves for 4 patient groups according to the performance of surgical ablation and the choice of prosthetic valve type. After adjusting for the key risk factors affecting survival (Table 5), the curves demonstrated that the use of surgical ablation, but not the choice of prosthetic valve type, significantly affected the long-term survival rate (HR, 2.085; 95\% CI, 1.04-4.18; $P=.038$; Figure 4, $B$ ).

\section{Subgroup Analysis for Mortality}

Figure 5, $A$ and $B$, show the all-cause mortality for each risk subgroup according to the multivariate risk factors listed in Table 5. After adjusting for prespecified covariates using the propensity score adjustment models in each subgroup, trends were observed for a greater risk of death associated with the absence of surgical ablation in most subgroups (Figure 5, A). In particular, a significant reduction in mortality by surgical ablation was observed in patients with bioprosthetic valve implantation (HR, 0.54; $P=.027$ ), low ejection fraction (HR, 0.37; $P=.041$ ), and mitral valve implantation (HR, 0.52; $P=.027)$. However, the choice of prosthetic valve type did not show survival trends favoring either type of prosthesis in any subgroup (Figure 5, $B$ ).

\section{DISCUSSION}

$\mathrm{AF}$ is the most common arrhythmia associated with valvular heart disease necessitating surgical treatment. The presence of AF has been reported to have an adverse influence on survival ${ }^{13}$ and cardiovascular-related complications in patients undergoing valve replacement surgery. ${ }^{5,14,15}$ In this context, the addition of surgical ablation in patients with valvular $\mathrm{AF}$ appears to have theoretical clinical benefits. However, the benefits of the routine performance of surgical ablation has been 

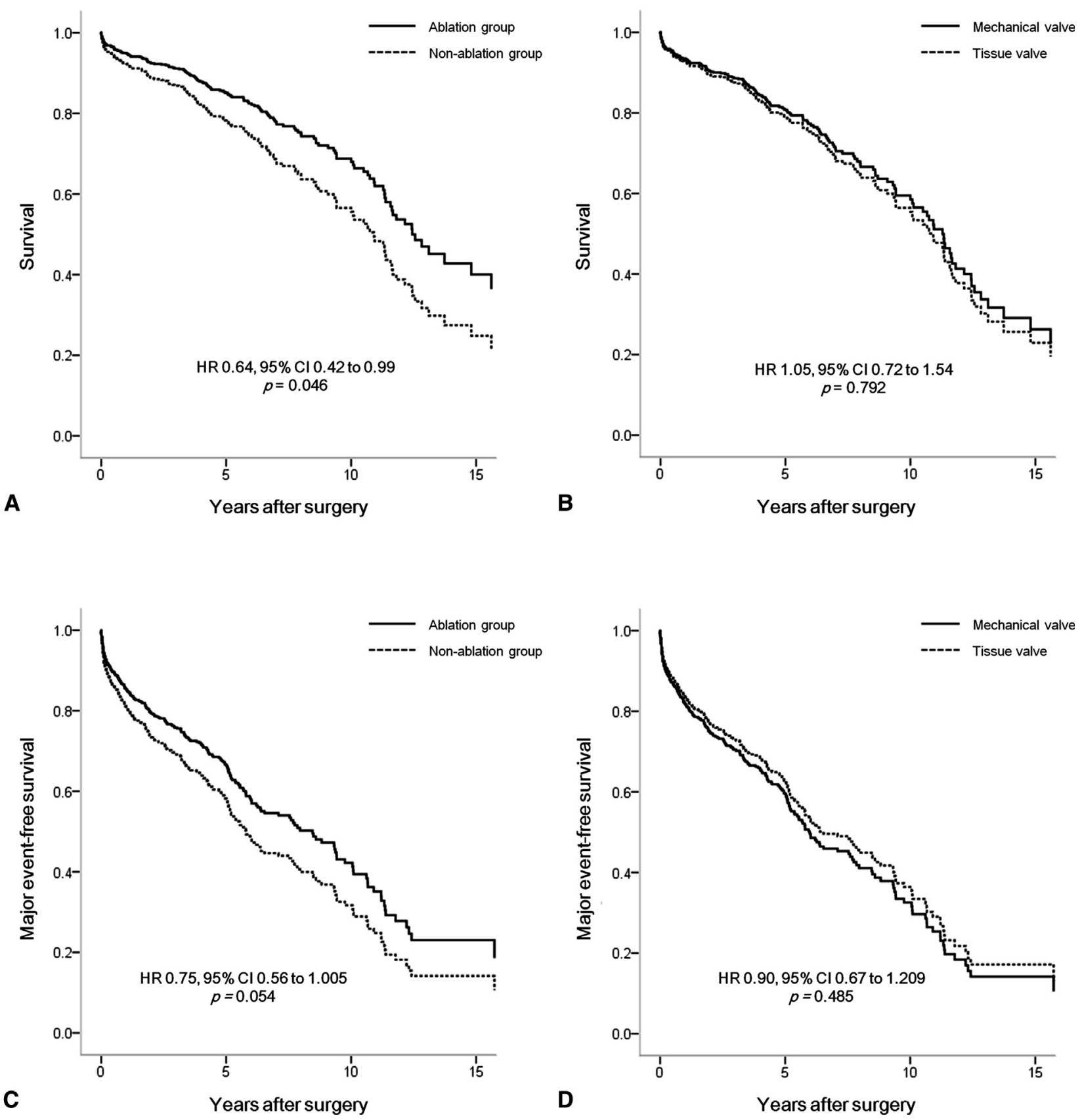

FIGURE 3. Survival curves adjusted by weighted Cox proportional hazards regression models and propensity score for all-cause mortality according to the A, performance of surgical ablation, B, valve type, C, event-free survival according to the performance of surgical ablation, and D, event-free survival stratified by valve type. Major adverse valve-related events included thromboembolic events, bleeding, operated valve endocarditis, and reoperation. $H R$, Hazard ratio; $C I$, confidence interval.

controversial because the surgical risks can be increased owing to the procedural complexity and longer cardiac ischemic time, especially for high-risk groups such as older individuals. ${ }^{5,16-18}$

Previous studies on the outcomes of using different prosthetic valve types in older patients found no meaningful between-group differences in the survival rates or incidence of complications. ${ }^{19-21}$ These cited studies, however, did not analyze the clinical outcomes in a group with additional risks of thromboembolism, such as AF, which is important owing to its high prevalence in this population. ${ }^{4}$ The advent of surgical ablation, with its high probability of restoring sinus rhythm, makes the decision of prosthetic valve type more complex for older patients with valvular $\mathrm{AF}$; a bioprosthetic valve would have been routinely recommended if $\mathrm{AF}$ did not coexist. ${ }^{1-3,22}$ Bioprosthetic 

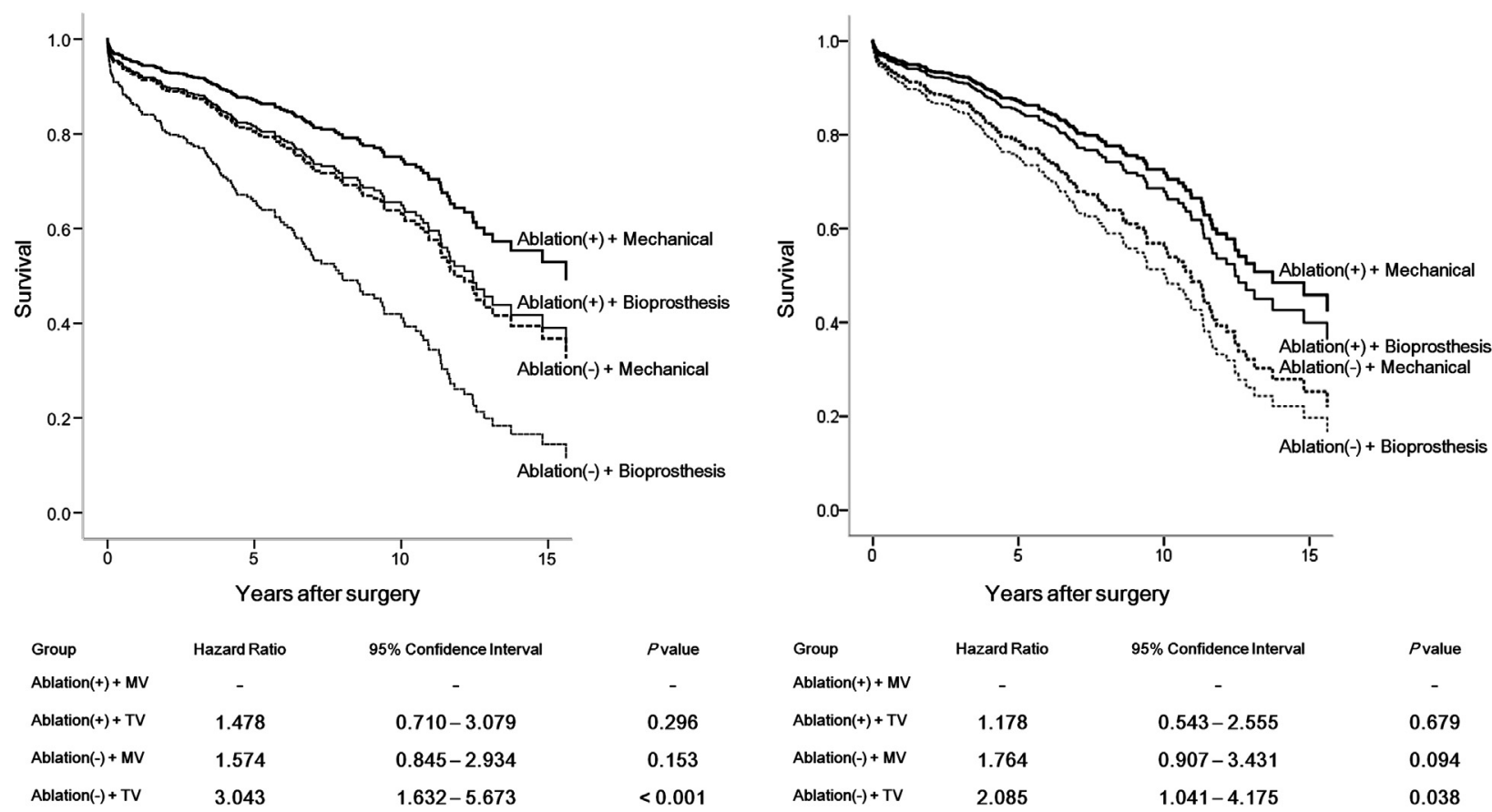

$\begin{array}{lccc}\text { Group } & \text { Hazard Ratio } & 95 \% \text { Confidence Interval } & P \text { value } \\ \text { Ablation }(+)+\mathrm{MV} & - & - & - \\ \text { Ablation }(+)+\mathrm{TV} & 1.478 & 0.710-3.079 & 0.296 \\ \text { Ablation(-)+ MV } & 1.574 & 0.845-2.934 & 0.153 \\ \text { Ablation(-)+ TV } & 3.043 & 1.632-5.673 & <0.001\end{array}$

A

B

FIGURE 4. A, Unadjusted and B, adjusted survival curves for all-cause mortality of each subgroup. The subgroups were divided according to the performance of surgical ablation and prosthetic valve type. Adjustment was conducted using Cox proportional hazards regression models. $M V$, Mitral valve; $T V$, tricuspid valve.

valve replacement without surgical ablation requires "lifelong anticoagulation therapy," nullifying the most important benefit of bioprosthetic valve implantation. Bioprosthetic valve replacement, combined with surgical ablation, seems to be an ideal option for this particular patient cohort. However, the efficacy of AF elimination has been reported to be lower for older patients with giant left atria than for younger patients, ${ }^{7}$ and the combination of surgical ablation could increase the risks of surgery in these vulnerable patients.

The benefit of combining mechanical valve replacement with surgical ablation for older patients has been debated. It has been questioned whether additional surgical ablation might further reduce the thromboembolic risks or other cardiovascular-related complications. Simply, mechanical valve replacement without surgical ablation might be sufficient; however, chronic AF has been reported to have deleterious effects on ventricular function, ${ }^{13,23}$ which can be associated with heart failure or troublesome rhythm-related problems long after surgery.

In the present study, we found that surgical ablation combined with valve replacement surgery for older patients with AF yielded superior survival rates, regardless of the type of prosthetic valve implanted. These findings suggest that the performance of surgical ablation is important for improving survival but that the choice of prosthetic valve type is not crucial.
Recent studies on the safety of surgical ablation have revealed that the procedure did not increase perioperative morbidity and risks when combined with major heart surgery. ${ }^{5,16}$ Although combining surgical ablation with valve replacement should be done with caution for high-risk patient groups, we believe that the benefits of surgical ablation on survival far outweigh the deleterious effects of the prolonged ischemic time and increased extent of surgery.

Our study has showed that the survival benefits of surgical ablation were more prominent in the subgroup with LV dysfunction (Figure 5, A). LV dysfunction is known to be associated with increased surgical mortality and morbidity in patients undergoing cardiac surgery. ${ }^{14}$ Thus, performing surgical ablation in this group has been controversial. However, it has been demonstrated that restoring atrial contraction and atrioventricular synchrony by the addition of surgical ablation can increase cardiac output and delay the progression of heart failure. ${ }^{15,23}$ This could account for the marked survival benefit to patients with LV dysfunction in our subgroup analysis. This finding indicates that surgical ablation can be performed with an acceptable safety profile in this high-risk group.

Lifelong anticoagulation therapy after valve replacement surgery is an important determining factor in the choice of prosthetic valve type, when surgical ablation is involved. For the group with bioprosthetic valve implantation, the 


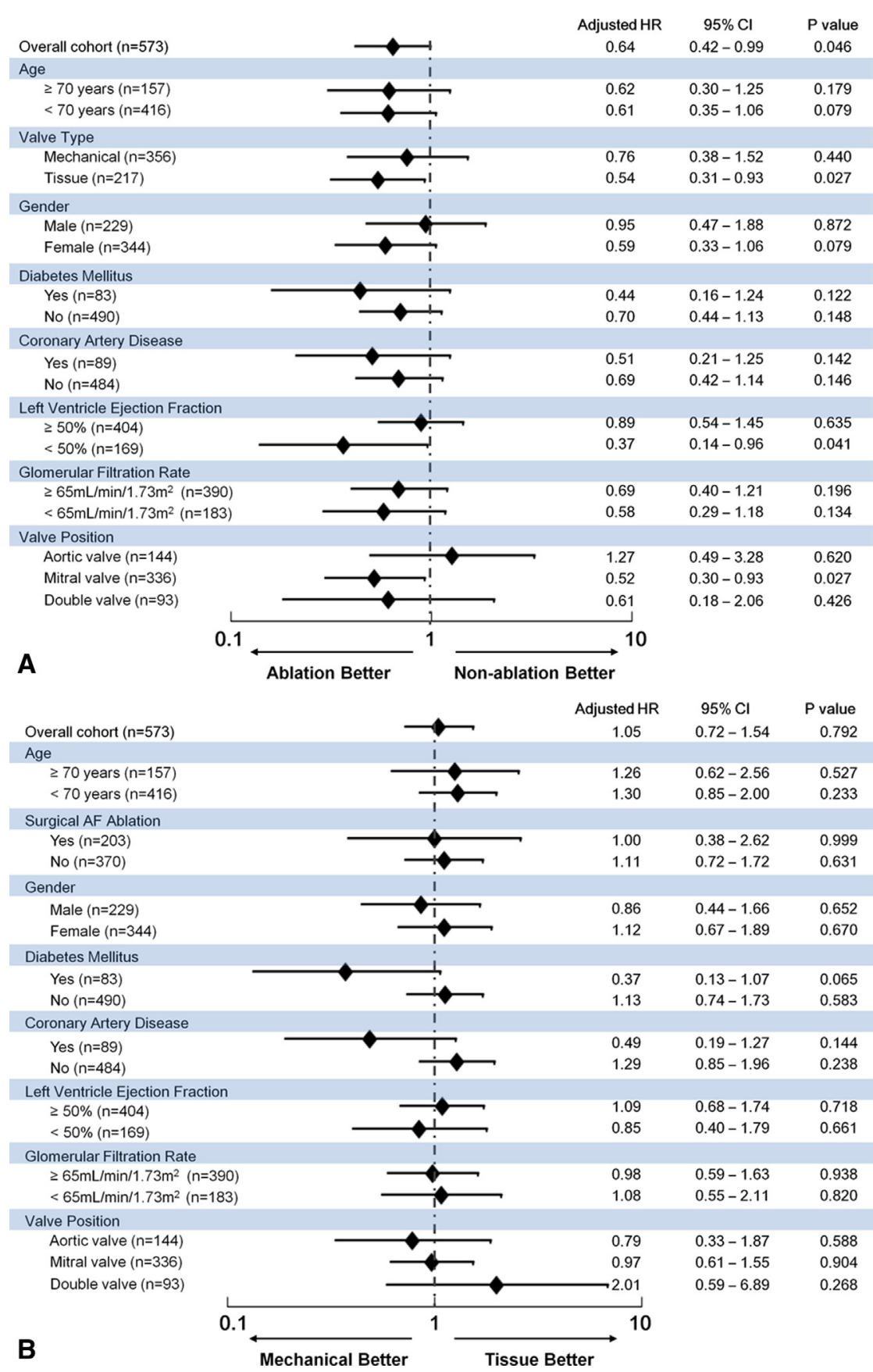

FIGURE 5. A, Adjusted hazard ratios (HRs) for all-cause mortality according to A, the performance of surgical ablation in subgroups according to multivariate risk factors, and $\mathrm{B}$, the choice of prosthetic valve type in subgroups according to multivariate risk factors. HRs were adjusted by weighted Cox proportional hazards regression models and propensity scores. $C I$, Confidence interval; $A F$, atrial fibrillation.

requirements for anticoagulation therapy can be reduced or eliminated after restoration of sinus rhythm by surgical ablation. Discontinuation of anticoagulation can be of great benefit to older patients by reducing the risks of major bleeding. ${ }^{24}$ Our subgroup analysis showed significant survival benefits with the addition of surgical ablation to the bioprosthetic valve group (Figure 5, A). This result could be attributed to (1) a lowered risk of thromboembolism inherent to AF owing to the restoration of sinus rhythm; (2) a reduced rate of anticoagulation-related hemorrhagic complications; and (3) improved hemodynamic performance with surgical ablation. ${ }^{23}$ Along with the "no-need-for-anticoagulation," the significant survival benefits of surgical ablation in the bioprosthetic 
valve group should be considered when deciding the prosthetic valve type for older patients with valvular AF.

In contrast to the bioprosthetic valve group, the theoretical benefits of surgical ablation in the mechanical valve group could have been limited by the inevitable lifelong anticoagulation therapy required. However, the beneficial effects of improved LV and tricuspid valve function and a reduced risk of thromboembolic events after surgical AF ablation in patients undergoing mechanical valve replacement have been previously reported. ${ }^{8,17,18,23}$ In support of these results, the present study has shown that concomitant AF ablation revealed a trend toward favorable survival in patients undergoing mechanical valve replacement $(\mathrm{HR}, 0.76)$ although it did not reach statistical significance $(P=.44)$. Pending the results from studies of a larger population, we believe that AF ablation should be always considered, even in older patients undergoing mechanical valve replacement, to improve the overall clinical and hemodynamic outcomes and to realize the consequent potential survival benefits.

Previous studies on the clinical effect of choosing different prosthetic valve types have shown mixed results regarding survival and postoperative complications. $^{1-3,22,25}$ In our study, the difference in survival rates according to prosthetic valve types (Figure $2, B$ ) was mainly attributed to age, but it disappeared after appropriate statistical adjustments (Figure 3, B). In addition, our subgroup analysis showed that the survival benefits did not favor any particular prosthetic valve type (Figure 5, $B)$. Both results indicate that survival does not vary according to the prosthetic valve type. Therefore, the choice of prosthetic valve type should be made, considering the overall conditions of the patient and the feasibility of surgical ablation for older patients with valvular AF.

\section{Study Limitations}

This was a retrospective and nonrandomized study of observational data. Hence, the results could have been influenced by unmeasured confounders, despite rigorous statistical adjustments. In addition, the present study incorporated 20 years of data, implicating the lack of uniformity of surgical ablation in terms of ablated atrial lesions and ablation energy sources. In addition, the study population included a mixed bag of cases, including single- and double-valve replacements, with and without CABG and aortic and mitral positions. This heterogeneity of the study population could have affected the study results.

\section{CONCLUSIONS}

Long-term survival after valve replacement surgery in older patients with AF will be affected by several preoperative characteristics, such as diabetes, coronary artery disease, heart failure, and the addition of surgical ablation, but not by the choice of prosthetic valve type.
Our findings suggest that surgical AF ablation should always be considered as a concomitant procedure for older patients with valvular AF, with a liberal choice of prosthetic valve type according to the conditions and expectations of the patient, not the perceived superiority of 1 valve type to another.

\section{References}

1. Hammermeister KE, Sethi GK, Henderson WG, Oprian C, Kim T, Rahimtoola SH. A comparison of outcomes in men 11 years after heart-valve replacement with a mechanical valve or bioprosthesis. N Engl J Med. 1993; 328:1289-96.

2. Rahimtoola SH. Choice of prosthetic heart valve for adult patients. J Am Coll Cardiol. 2003;41:893-904.

3. Rahimtoola SH. Choice of prosthetic heart valve in adults: an update. J Am Coll Cardiol. 2010;55:2413-26.

4. Jessurun ER, van Hemel NM, Kelder JC, Elbers S, de la Riviere AB, Defauw JJ, et al. Mitral valve surgery and atrial fibrillation: is atrial fibrillation surgery also needed? Eur J Cardiothorac Surg. 2000;17:530-7.

5. Calkins H, Kuck KH, Cappato R, Brugada J, Camm AJ, Chen SA, et al. 2012 HRS/EHRA/ECAS expert consensus statement on catheter and surgical ablation of atrial fibrillation: recommendations for patient selection, procedural techniques, patient management and follow-up, definitions, endpoints, and research trial design. Europace. 2012;14:528-606.

6. Gillinov AM, Sirak J, Blackstone EH, McCarthy PM, Rajeswaran J, Pettersson G, et al. The Cox maze procedure in mitral valve disease: predictors of recurrent atrial fibrillation. J Thorac Cardiovasc Surg. 2005;130: 1653-60.

7. Lee SH, Kim JB, Cho WC, Chung CH, Jung SH, Choo SJ, et al. The influence of age on atrial fibrillation recurrence after the maze procedure in patients with giant left atrium. J Thorac Cardiovasc Surg. 2011;141:1015-9.

8. Kim JB, Moon SJ, Yun SC, Kim KW, Jung SH, Choo SJ, et al. Long-term outcomes of mechanical valve replacement in patients with atrial fibrillation: impact of the maze procedure. Circulation. 2012;125:2071-80.

9. Kim JB, Bang JH, Jung SH, Choo SJ, Chung CH, Lee JW. Left atrial ablation versus biatrial ablation in the surgical treatment of atrial fibrillation. Ann Thorac Surg. 2011;92:1397-404; discussion 1404, 1395.

10. Lauer MS, Blackstone EH, Young JB, Topol EJ. Cause of death in clinical research: time for a reassessment? J Am Coll Cardiol. 1999;34:618-20.

11. Akins CW, Miller DC, Turina MI, Kouchoukos NT, Blackstone EH, Grunkemeier GL, et al., Councils of the American Association for Thoracic Surgery, Society of Thoracic Surgeons, European Association for CardioThoracic Surgery, Ad Hoc Liaison Committee for Standardizing Definitions of Prosthetic Heart Valve Morbidity. Guidelines for reporting mortality and morbidity after cardiac valve interventions. J Thorac Cardiovasc Surg. 2008; 135:732-8.

12. Kurth T, Walker AM, Glynn RJ, Chan KA, Gaziano JM, Berger K, et al. Results of multivariable logistic regression, propensity matching, propensity adjustment, and propensity-based weighting under conditions of nonuniform effect. Am J Epidemiol. 2006;163:262-70.

13. Benjamin EJ, Wolf PA, D'Agostino RB, Silbershatz H, Kannel WB, Levy D. Impact of atrial fibrillation on the risk of death: The Framingham heart study. Circulation. 1998;98:946-52.

14. Bonow RO, Carabello BA, Chatterjee K, de Leon AC Jr, Faxon DP, Freed MD, et al., American College of Cardiology/American Heart Association Task Force on Practice Guidelines. 2008 Focused update incorporated into the ACC/AHA 2006 guidelines for the management of patients with valvular heart disease: a report of the American College of Cardiology/American Heart Association Task Force on Practice Guidelines (Writing Committee to revise the 1998 guidelines for the management of patients with valvular heart disease). Endorsed by the Society of Cardiovascular Anesthesiologists, Society for Cardiovascular Angiography and Interventions, and Society of Thoracic Surgeons. J Am Coll Cardiol. 2008;52:e1-142.

15. Schulenberg R, Antonitsis P, Stroebel A, Westaby S. Chronic atrial fibrillation is associated with reduced survival after aortic and double valve replacement. Ann Thorac Surg. 2010;89:738-44.

16. Ad N, Henry L, Hunt S, Holmes SD. Do we increase the operative risk by adding the Cox maze III procedure to aortic valve replacement and coronary artery bypass surgery? J Thorac Cardiovasc Surg. 2012;143:936-44. 
17. Bando K, Kasegawa H, Okada Y, Kobayashi J, Kada A, Shimokawa T, et al. Impact of preoperative and postoperative atrial fibrillation on outcome after mitral valvuloplasty for nonischemic mitral regurgitation. J Thorac Cardiovasc Surg. 2005;129:1032-40.

18. Bando K, Kobayashi J, Kosakai Y, Hirata M, Sasako Y, Nakatani S, et al. Impact of Cox maze procedure on outcome in patients with atrial fibrillation and mitral valve disease. J Thorac Cardiovasc Surg. 2002;124:575-83.

19. Brown ML, Schaff HV, Lahr BD, Mullany CJ, Sundt TM, Dearani JA, et al. Aortic valve replacement in patients aged 50 to 70 years: improved outcome with mechanical versus biologic prostheses. J Thorac Cardiovasc Surg. 2008; 135:878-84; discussion 884.

20. Schelbert EB, Vaughan-Sarrazin MS, Welke KF, Rosenthal GE. Valve type and long-term outcomes after aortic valve replacement in older patients. Heart. 2008;94:1181-8.

21. Stassano P, Di Tommaso L, Monaco M, Iorio F, Pepino P, Spampinato N, et al. Aortic valve replacement: a prospective randomized evaluation of mechanical versus biological valves in patients ages 55 to 70 years. J Am Coll Cardiol. 2009;54:1862-8.

22. Hammermeister KE, Sethi GK, Henderson WG, Grover FL, Oprian C, Kim T, et al. Outcomes 15 years after valve replacement with a mechanical versus a bioprosthetic valve: final report of the Veterans Affairs randomized trial. J Am Coll Cardiol. 2000;36:1152-8.

23. Stulak JM, Dearani JA, Daly RC, Zehr KJ, Sundt TM III, Schaff HV Left ventricular dysfunction in atrial fibrillation: restoration of sinus rhythm by the Cox-maze procedure significantly improves systolic function and functional status. Ann Thorac Surg. 2006;82:494-500; discussion 500,491

24. Medi C, Hankey GJ, Freedman SB. Stroke risk and antithrombotic strategies in atrial fibrillation. Stroke. 2010;41:2705-13.

25. Bloomfield P, Wheatley DJ, Frescott RJ, Miller HC. Twelve-year comparison of a Bjork-Shiley mechanical heart valve with porcine bioprostheses. N Engl J Med. 1991;324:573-9. 